\title{
Methane to Methanol in Supercritical Water
}

\author{
Phillip E. Savage, ${ }^{\star}$ Ruokang Li, and John T. Santini, Jr. \\ University of Michigan, Department of Chemical Engineering, \\ Ann Arbor, MI 48109-2136
}

\author{
Received July 8, 1993; accepted in revised form April 4, 1994
}

We examined the feasibility of producing methanol from the partial oxidation of methane in nearcritical and supercritical water. Oxygen was always the limiting reactant. The parameter space investigated experimentally included temperatures between 349 and $481^{\circ} \mathrm{C}$, batch holding times between 1 and 9 min, water densities between 0.15 and $0.35 \mathrm{~g} \mathrm{~mL}^{-1}$, initial methane to water molar ratios between 0.05 and 0.27 , and initial methane to oxygen molar ratios between 10 and 26. Experiments within this parameter space led to methane conversions up to $6 \%$, and oxygen conversions up to $100 \%$. Methanol, carbon monoxide, and carbon dioxide were the major products. The methanol selectivities ranged from 0.04 to 0.75 , with the highest selectivities occurring at the lower conversions. The highest methanol yield was $0.7 \%$. Reactions performed in glass-lined reactors proceeded to higher conversions than did reactions in stainless-steel reactors under otherwise identical conditions. A detailed chemical kinetics model showed that the methanol selectivity increased with temperature and with the methane to oxygen molar ratio, but decreased with increasing oxygen conversion. The methanol yield showed the same trends with temperature and the methane to oxygen ratio, but the yield increased with oxygen conversion.

Keywords: supercritical water, methane, partial oxidation, mechanism, modeling

\section{INTRODUCTION}

Supercritical fluids (SCFs) are an attractive medium for conducting chemical reactions because one can adjust the reaction environment (e.g., solvent properties) by manipulating temperature and pressure. Several fundamental investigations of reactions in SCFs have been conducted to explore these opportunities and to probe the influence of the SCF. A number of different $\mathrm{SCFs}^{1-5}$ such as $\mathrm{CO}_{2}$, ethane, trifluoromethane, propane, 1,1-difluoroethane, and toluene have been used in investigations of the fundamentals. Much of the previous SCF reaction work with a more technological focus, however, has dealt with supercritical water (SCW). The types of reactions considered include acid-catalyzed dehydration of alcohols, ${ }^{6-}$ ${ }^{8}$ pyrolysis and hydrolysis of coal and biomass model compounds, ${ }^{9-16}$ reactions of geochemical significance, ${ }^{17}$ oxidative destruction of organics, ${ }^{18-24}$ electrochemical reactions, ${ }^{25,26}$ and partial oxidation of methane. ${ }^{27,28}$

Using SCW as a medium for methane conversion is an interesting proposition because it provides a fresh approach to the problem of converting methane to high yields of oxygenates or higher hydrocarbons. The fundamental problem with existing catalytic and homogeneous gas-phase schemes is that the target products (methanol, ethane, or ethylene) are more reactive than methane so conditions that promote methane conversion promote even more rapid degradation of the desired products. Extensive research in this field has now made it clear that incremental improvements in the existing schemes will probably not lead to the high yields required for commercial viability. ${ }^{29,30}$ Novel approaches are required to overcome this fundamental barrier. Taking advantage of the unique properties of supercritical fluids and the opportunity they provide to manipulate the reaction environment might represent one such novel approach. It is near a fluid's critical point that the properties of SCFs are the most sensitive to small changes in temperature and pressure. Thus, water, which has a critical temperature of $374{ }^{\circ} \mathrm{C}$, could be a good medium for methane conversion to methanol because this process occurs in the gas phase at high pressures and at a temperature around $400^{\circ} \mathrm{C}$.

Several investigators have examined the reactions of methane with oxygen in SCW. Steeper et al. ${ }^{31}$ discussed the qualitative features of methane diffusion flames in SCW. Webley and Tester $^{21}$ oxidized methane in SCW with the goal of converting the organic carbon to $\mathrm{CO}_{2}$. They provided a global rate law for the oxidation kinetics and developed a reaction mechanism to explore the reac- 
tion fundamentals. Rofer and Streit ${ }^{32,33}$ reported results from a similar modeling study. Franck ${ }^{27}$ appears to have been the first to report quantitative results for the formation of methanol from the partial oxidation of methane in SCW. Dixon and Abraham ${ }^{28}$ reported on the catalytic partial oxidation of methane to methanol in SCW. In this paper we present experimental and modeling results for the homogeneous partial oxidation of methane to methanol in SCW.

\section{EXPERIMENTAL}

Materials. All chemicals used in this research were obtained commercially and used as received. Methane was from Scott Specialty Gases in a nominal purity of $99.99 \%$. The water was distilled, deionized, and degassed prior to use in the experiments.

The reactors, which were fabricated from stainlesssteel Swagelok tube fittings, had an internal volume of $2.0 \mathrm{~cm}^{3}$. The body of the reactor consisted of a 3/8-in. port connector sealed with a $3 / 8$-in. cap at one end and a $3 / 8$-in. to $1 / 8$-in. reducing union at the opposite end. A length of $1 / 8$-in. o.d. tubing (about 10 in.) connected the reactor body to a Whitey severe-service shut-off valve. A Swagelok quick-connect was attached to the other end of the valve. The matching end of the quick-connect was part of a gas distribution system used to load the reactor.

Methane, oxygen, and argon cylinders were installed in the gas distribution system so that we could load the reactor with the reactant gases and purge the transport lines with argon. The numbers of moles of methane and oxygen added to the reactor were calculated from the Peng-Robinson equation of state.

Procedure. A carefully measured volume $( \pm 1$ $\mu \mathrm{L}$ ) of water was added to the reactor body using a syringe. The amount of water added set the water density at reaction conditions. The reactor body was then attached to the valve assembly and the fully assembled batch reactors were individually attached to the gas-distribution system.

Oxygen was added to the reactor first, and the pressure on the two-stage regulator was set at the value that would load the desired number of moles of oxygen into the reactor. These oxygen pressures ranged from 24 to 129 psi. After adding oxygen, the gas transport lines were purged with flowing argon, and then methane was added to the reactor. $\Lambda$ gain, setting the pressure on the cylinder regulator controlled the number of moles of methane added to the reactor. The methane pressures used were between 330 and 1630 psi. We estimate the uncertainties in the measured oxygen and methane pressures to be about \pm 1 psi and $\pm 10 \mathrm{psi}$, respectively.

After the reactor was loaded with water, oxygen, and methane, it was removed from the gas-distribution system and placed in a preheated, isothermal, fluidized sand bath. We estimate the reactor heat-up time to be 1-2 min. The reactors remained in the sand bath for the desired total batch holding time, and then they were removed and rapidly cooled in cold water. After reaching room temperature, the reactors were vented into a glass gas-sampling bulb, the pressure was measured to verify that the reactor had not leaked, and the gas phase was analyzed by gas chromatography. The aqueous-phase products remaining in the reactor were recovered from the disassembled reactor body and then analyzed by the complementary methods of gas chromatography (GC) with flame ionization and mass spectrometric detection and by high-performance liquid chromatography (HPIC) with a UV detector. The reactors were thoroughly cleaned with acetone and then dried in an oven at about $100^{\circ} \mathrm{C}$ for at least $1 \mathrm{~h}$ between successive experiments.

Analytical Chemistry. Hewlett-Packard model $\mathbf{5 8 9 0}$ gas chromatographs were used to analyze the reaction products. A 10-port Valco valve injected a 0.5 $\mathrm{mL}$ sample of the gas-phase products into a $10-\mathrm{ft} \times 1 / 8$ in. o.d. Supelco Carbosieve S-II permanent gas column. The sample constituents were observed by a thermal conductivity detector. Helium flowing at $20 \mathrm{~mL} \mathrm{~min}^{-1}$ served as the carrier gas. The GC oven temperature was held at $35^{\circ} \mathrm{C}$ for $7 \mathrm{~min}$ and then increased to $225^{\circ} \mathrm{C}$ at a rate of $16{ }^{\circ} \mathrm{C} \mathrm{min}{ }^{-1}$. Detector response factors for oxygen, methane, carbon dioxide, and carbon monoxide were determined experimentally using calibration gas mixtures from Scott Specialty Gases.

The components in the aqueous phase were separated using a 1/4-in. glass column packed with $80 / 100$ mesh HayeSep P. Helium served as the carrier gas, the oven temperature was isothermal at $150^{\circ} \mathrm{C}$, and the sample constituents were observed by a flame-ionization detector. The detector response factor for methanol was determined experimentally. The same glass column was installed into a Hewlett-Packard GC-MS system to verify the identity of the methanol peak. A jet separator served as the interface between the GC and MS components of this system. The HPLC was equipped with a Supelcogel $\mathrm{C} 610 \mathrm{H}$ organic acids column $(30 \mathrm{~cm} \times 7.8-\mathrm{mm}$ i.d. $)$ and a $0.1 \% \mathrm{H}_{3} \mathrm{PO}_{4}$ aqueous solution flowing at $1.0 \mathrm{~mL} \mathrm{~min}^{-1}$ was the mobile phase. The UV detector was set at 210 $\mathrm{nm}$.

\section{EXPERIMENTAL DESIGN}

We desired to determine the influence of five different variables (temperature, time, water density, methane to water molar ratio, and methane to oxygen molar ratio) on the conversion of methane to methanol in SCW. The literature on the high-pressure, gas-phase conversion of methane to methanol provided some guidance to values of these variables that led to high methanol yields. We considered the following ranges for each of the independent variables: temperatures between 349 and $481{ }^{\circ} \mathrm{C}$, total batch holding times (including heat-up) between 1 and 9 min, initial methane to water molar ratios between 0.05 and 0.27 , initial methane to oxygen molar ratios between 10 and 26 , and nominal water densities between 0.15 and 


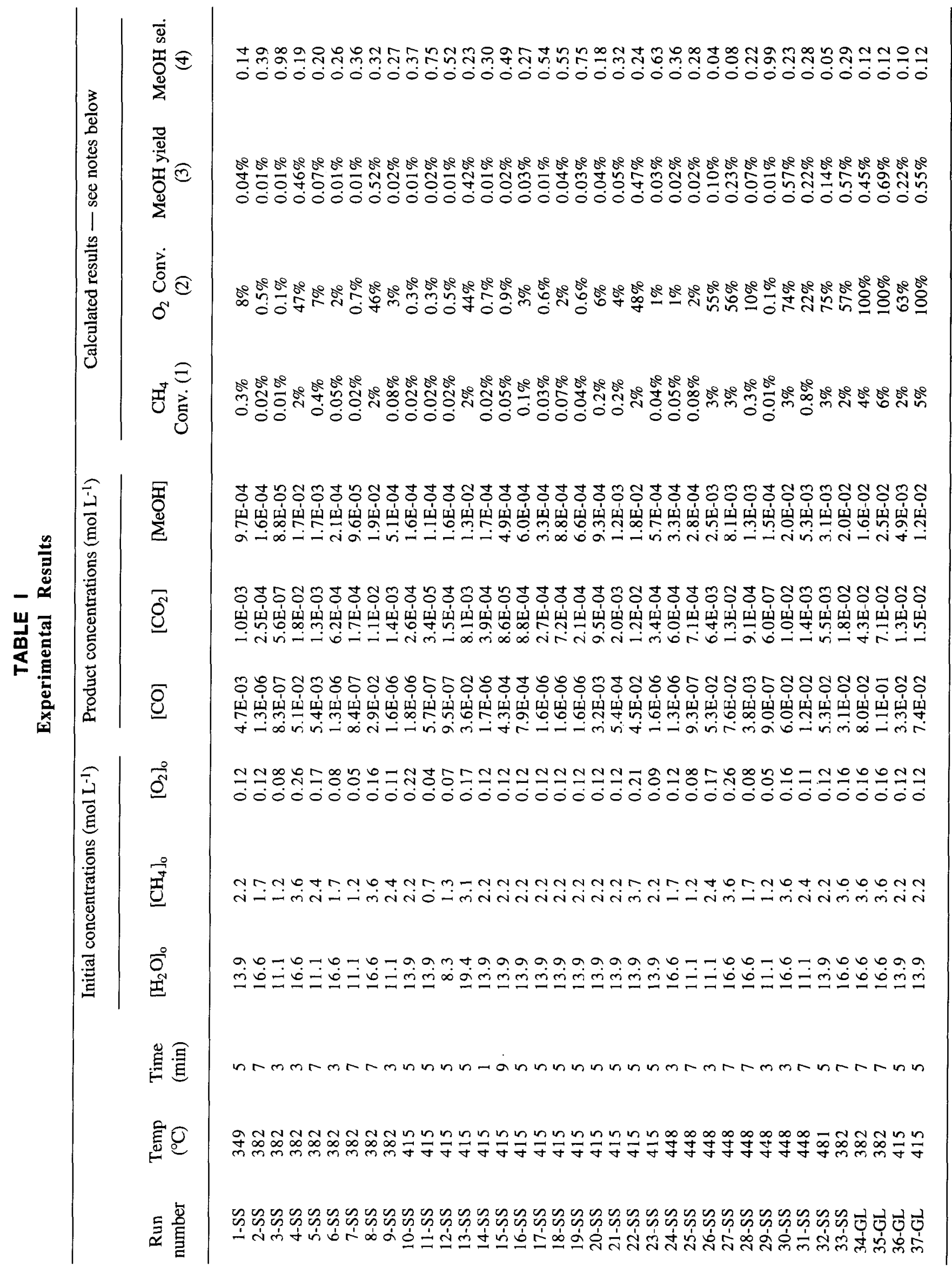




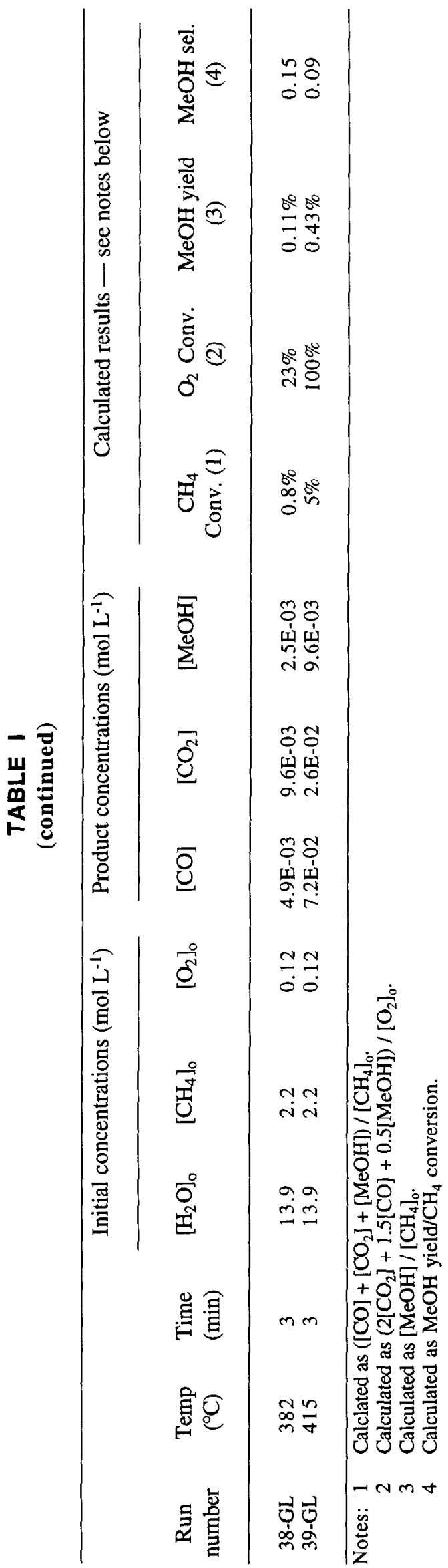

$0.35 \mathrm{~g} \mathrm{~mL}^{-1}$. Experimental constraints prevented us from examining a wider range for some of these variables. For example, the methane to oxygen ratio was limited by the maximum pressure of the methane cylinder and the minimum pressure we could accurately measure on the oxygen cylinder regulator. We designed 32 different experiments that probed the effect of each of the five independent variables at each of five equally spaced levels. ${ }^{34,35}$ The conditions for 16 of these trials were taken from a $16 \times 16$ Hadamard matrix, 10 of the trials constituted star points, and 6 of the planned trials were replicates of the center point.

\section{EXPERIMENTAL RESULTS}

Table I lists the conditions used in and the results of the methane oxidation experiments. The SS or GL tag that follows the Run number in Table I indicates whether the experiment used a stainless-steel or glass-lined reactor. The initial concentrations of methane, oxygen, and water were calculated as the number of moles of each compound loaded in the reactor divided by the reactor volume. Implicit in these calculations is the assumption that a single fluid phase exists at the reaction conditions. We checked this assumption by estimating the mixture critical temperature using $\mathrm{Li}$ 's method. ${ }^{36}$ The reaction temperature exceeded the estimated critical temperature for all experiments. The concentrations of methanol, $\mathrm{CO}$, and $\mathrm{CO}_{2}$ were determined from $\mathrm{GC}$ analyses, and all other results in Table I were calculated using these concentrations.

Before presenting and discussing the results we will first discuss the uncertainties in the results. The entries for Runs 16-21 show results for the six replicate expcriments at the center point. The standard deviation of the methanol concentrations was $39 \%$ of the mean value, whereas the standard deviation was $77 \%$ of the mean for $\mathrm{CO}_{2}$ and $165 \%$ of the mean for CO. It is clear that the methanol concentrations showed the greatest reproducibility and that analysis of the gas-phase products had a much larger uncertainty. Therefore, we have the most confidence in the methanol concentrations and yields that appear in Table I. The other calculated results in Table I have a higher uncertainty because they required the $\mathrm{CO}$ and $\mathrm{CO}_{2}$ concentrations. For example, the methane conversion was calculated as the sum of the concentrations of $\mathrm{CH}_{3} \mathrm{OH}, \mathrm{CO}$, and $\mathrm{CO}_{2}$ divided by the initial $\mathrm{CH}_{4}$ concentration. The standard deviation of the methane conversion was $75 \%$ of the mean for Runs $16-21$. The uncertainty in the oxygen conversion was comparable. This high uncertainty led to calculated oxygen conversions exceeding $100 \%$ in a few cases. In these cases, Table I gives the conversions as $100 \%$.

Because these uncertainties were high, we repeated other experiments to assess reproducibility. The conditions of Run 8 were repeated and the results appear as Run 33 in Table I. It is clear that the results from Runs 8 and 33 are in good agreement. Similarly, the pairs of Runs 
34 and 35 and Runs 36 and 37 are replicates in glass-lined reactors. We again see less variability in these replicates than we observed in Runs 16-21. The reason that the reproducibility was poorer in Runs 16-21 may be that these experimental conditions led to much lower conversions than did the conditions in Runs 8 and 33, 34, and 35, and 36 and 37 . Since the values being measured were small, the experimental error could appear to be large in comparison. Thus, the data at the very low conversions have the greatest uncertainty. For this reason we do not take the extremely high selectivities of 0.98 and 0.99 reported for Runs 3 and 29, where the oxygen conversion was $0.1 \%$, to be precise and accurate values. Moreover, another reason for the run-to-run variability is that it was not possible to reproduce exactly the same initial conditions for different runs. There was always some variability in the reactant loadings, even for nominally identical conditions.

The data for runs 1-33, which were accomplished in stainless-steel batch reactors, show that methanol selectivities comparable to those reported in gas-phase experiments ${ }^{37-42}$ were obtained under some of the experimental conditions in SCW. These high selectivities occurred only at very low methane conversions, however, so the methanol yields were always low. The highest yields in stainless-steel reactors were achieved in Run 30 and in Runs 8 and 33 . These maximal yields were about $0.5-$ $0.6 \%$ based on carbon and about $6 \%$ based on oxygen. These runs that gave the highest yields employed different temperatures and different batch holding times, but they shared the same nominal initial loadings of methane, oxygen, and water.

The results in Table I were used to identify the region of the parameter space that would lead to the highest methanol yield. The influence of each of the five different independent variables on the methanol yield was quantified using the correlation

$$
Y=b_{\mathrm{o}}+\sum_{i=1}^{5} b_{i} A_{i}+\sum_{i=1}^{5} b_{i i} A_{i}{ }^{2}+\sum_{i=1}^{5} \sum_{j=1 \neq i}^{5} b_{i j} A_{i} A_{j}
$$

where $Y$ represents the methanol yield, $A_{i}$ represents each of the independent variables, and the values of the subscripted $b$ parameters were determined empirically. This correlation was then used to locate the region of the response surface that provided optimal methanol yields. This analysis of the experimental data indicated that the optimal methanol yield would be $1.5 \%$ and that it would be obtained at $349^{\circ} \mathrm{C}$ and 9 minutes using a water density of $0.35 \mathrm{~g} \mathrm{~mL}^{-1}$, a methane to water ratio of 0.27 and a methane to oxygen ratio of 26 . Since the projected optimal methane yield was low, we did not attempt to confirm this result experimentally. Moreover, these conditions werc on the boundary of the parameter space we explored. Thus, it is conceivable that a set of conditions exists outside the parameter space explored that will lead to even higher methanol yields. Unfortunately, laboratory constraints prevented us from doing experiments outside the original parameter space.

In addition to quantifying the concentrations of methanol, $\mathrm{CO}$ and $\mathrm{CO}_{2}$, we also detected a few other reaction products in the complementary GC and HPLC analyses. These products, which did not appear in all of the samples and which were typically present in low concentrations were tentatively identified as acetaldehyde, ethanol, acetic acid, and formic acid.

The literature contains only two earlier accounts of the conversion of methane to methanol in SCW, but these do provide a basis for some limited comparisons. Franck ${ }^{27}$ oxidized methane in SCW at $380^{\circ} \mathrm{C}$ and 300 and 600 bar with a methane to water molar ratio of 0.43 . Methanol selectivities approaching $20 \%$ were reported. The selectivity increased nearly linearly with the molar ratio of methane to oxygen, and the selectivity was higher at the higher pressure. Franck also detected small amounts of formic acid and formaldehyde in the liquid phase.

Dixon and Abraham ${ }^{28}$ reported experimental results from the catalytic conversion of methane to methanol in SCW. Their experiments were conducted at $450^{\circ} \mathrm{C}$. The highest methanol yield they reported was slightly less than $4 \%$, and the corresponding methane conversion was about $10 \%$. These results were obtained with a methane to oxygen molar ratio of 13.8 and a 5 -min reaction time. They did not include results from uncatalyzed reactions in SCW so a direct comparison with the present results is not possible. Nevertheless, the methanol yields and the methane conversions reported by Dixon and Abraham are higher than those obtained in the present work. Therefore, it does appear that the presence of their $\mathrm{Cr}_{2} \mathrm{O}_{3}$ catalyst produced desirable effects.

Surface Effects. The literature on methane conversion to methanol via homogeneous gas-phase reactions has shown that the reactor surface material can influence the reaction. ${ }^{40-43}$ Burch et al., ${ }^{42}$ for instance, found that under otherwise identical reaction conditions, no methanol was observed in a stainless-steel reactor but high methanol selectivities were achieved in quartz and Pyrex reactors. Only after the system pressure exceeded $20 \mathrm{~atm}$ was methanol observed in the stainless-steel reactor. As the system pressure was increased further, the stainless steel reactor continued to give lower selectivities than the quartz and Pyrex reactor, but the difference in the selectivities became smaller. They concluded that the reactor surface has much less of an effect at high pressures.

Thomas et al. ${ }^{40}$ and Chun and Anthony ${ }^{43}$ reported that even a nominally inert material such as Pyrex produces a surface effect. The rate of methane conversion and the methanol selectivity decreased as the surface-to-volume $(\mathrm{S} / \mathrm{V})$ ratio increased. This observation was taken as evidence that Pyrex inhibits or quenches radical reactions. Chun and Anthony noted that operation at low S/V ratios 
and high pressures rendered these surface effects negligibly small.

We sought to determine whether surface effects were important for methane conversion in SCW. Therefore, we fitted the stainless-steel reactors described in the experimental section with a glass liner. The internal volume of these glass-lined reactors was $0.72 \mathrm{~cm}^{3}$. The results from experiments in the glass-lined reactor appear as Runs 34-39.

Runs 34 and 35 were done at the same nominal conditions as Runs 8 and 33, which had led to the highest methanol yields in the stainless-steel reactors. Comparing these two sets of data shows that the methanol yield was not appreciably different in the two reactors. The methanol selectivity was lower but the conversion was higher in the glass reactors so these two opposing effects combined to give roughly the same yield obtained in the stainless steel reactor.

Runs 36 and 37 were done at the same conditions as Runs 16-21. Comparing these two sets of data shows that the mean methanol yield in the glass-lined reactors was about an order of magnitude higher than the mean yield in the stainless-steel reactors. The methanol selectivities were lower, but the methane and oxygen conversions were much higher. Thus, these limited experiments suggest that glass-lined reactors led to higher methane conversions but lower methanol selectivities than did stainless-steel reactors.

Interpreting these results and comparing them with the literature is complicated by two factors. One is that the literature provides information primarily on the effect of surfaces on the methanol selectivity rather than the yield, which is the quantity we could measure most accurately. The second complicating factor is that the stainless steel and glass-lined reactors we used differed not only in their surface materials but also in their S/V ratios. Thus, two variables changed simultaneously. Nevertheless, we note that the reduction in methanol selectivity observed here is precisely the opposite of what Burch et al. ${ }^{42}$ observed for reactions in glass and in stainless steel. We also note that Thomas et al ${ }^{40}$ found that increasing the $S / V$ ratio significantly decreased both the rate and the methanol selectivity, and therefore the methanol yield. The present results for methane conversion in SCW, on the other hand, show that the methanol yield was either unchanged or enhanced by using the glass-lined reactors.

\section{MECHANISTIC MODELING}

Having experimentally investigated methane oxidation in SCW, we next used a complementary approach, a mechanistic reaction model, to explore the feasibility of converting methane to methanol in SCW. Webley and Tester ${ }^{21}$ developed a free-radical reaction mechanism for the oxidation of methane in SCW at temperatures well above the critical temperature. Their model was based on gas-phase combustion mechanisms and kinetics for

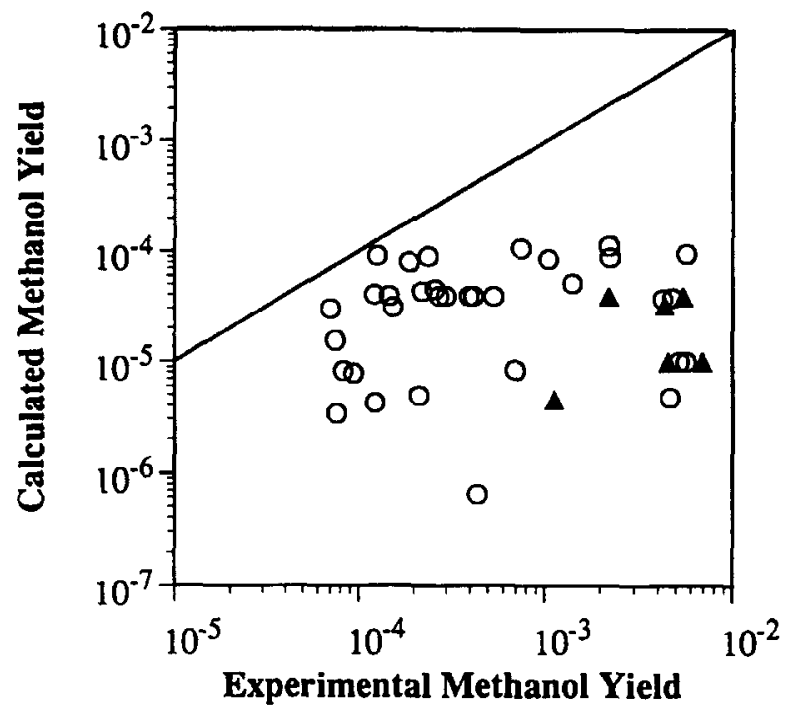

Figure 1. Comparison of experimental and predicted methanol yields

methane. We have adopted this model for the present investigation.

The reaction mechanism consists of 66 elementary free-radical reaction steps. We used the rate constants for the forward reactions that were listed by Webley and Tester. ${ }^{21}$ The rate constants for the reverse reactions were then calculated from these forward reaction rate constants and the concentration-based equilibrium ratio, $K_{\mathrm{c}}$.

$$
K_{\mathrm{c}}=\frac{K_{\mathrm{p}}}{(Z R T)^{\Sigma v_{i}}} .
$$

We used Webley and Tester's ${ }^{44}$ values for $K_{\mathrm{p}}$, and we calculated the compressibility factor, $Z$, for the reaction mixture from the Peng-Robinson equation of state. All binary interaction parameters were set equal to zero. This development neglected the effects of fluid-phase nonidealities on the equilibrium constant for we took the fugacity coefficients for all species to be equal to unity.

We used Acuchem, ${ }^{45}$ a software package for modeling isothermal reactions in constant-volume systems, to solve the differential equations that describe the variations of the species concentrations with time. We reproduced some of the modeling results reported in the literature ${ }^{21}$ prior to using the model in this study.

Our primary goal in this modeling work was to explore the parameter space and not to develop a reaction model that provided quantitative prediction of the experimental results. Nevertheless, it is instructive to compare the experimental results with the model predictions for identical reaction conditions. Figures 1 and 2 provide this comparison for the methanol yield and selectivity. If all of the model predictions were in perfect accord with the experiments then all of the data would fall on the solid lines in these Figures. The filled triangles correspond to 


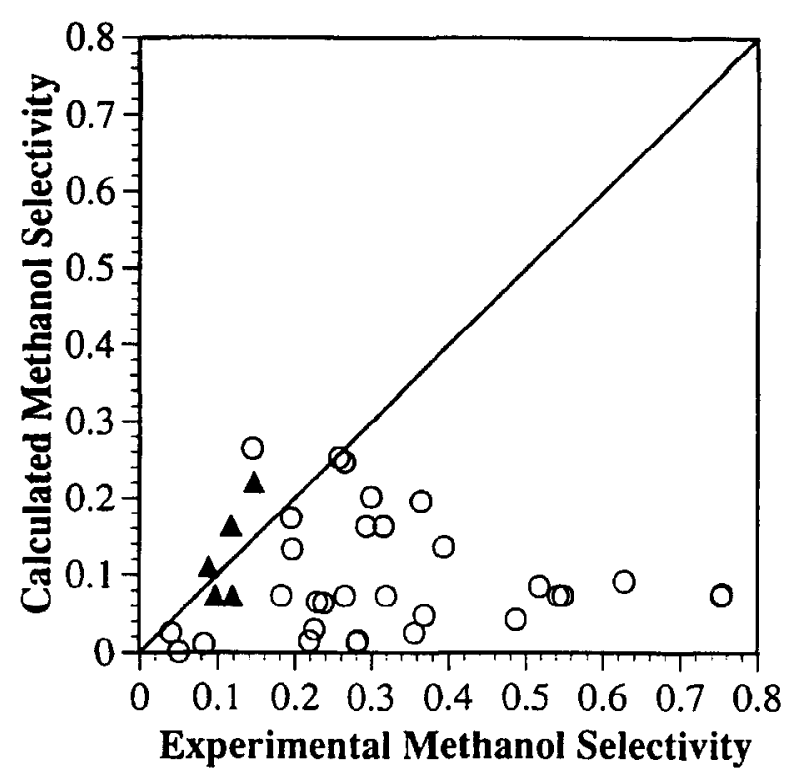

Figure 2. Comparison of experimental and predicted methanol sclcctivities

experiments in glass-lined reactors and the unfilled circles represent experiments in stainless-steel reactors.

Figure 1 shows that the predicted methanol yields were always lower than the experimental yields, and the model and experimental yields often differed by more than an order of magnitude. Figure 2 shows that the model did not predict any methanol selectivities greater than 0.3 , but selectivities higher than 0.3 were observed experimentally. The predicted selectivities were lower than the experimental values for all but two of the reactions done in stainless-steel reactors, but the calculated and experimental selectivities were in much better agreement for the reactions done in glass-lined reactors.

This comparison of modeling and experimental results shows that the model did not provide accurate quantitative predictions of experimental results. This lack of agreement is not entirely surprising, however, and it can be attributed to any of several possible causes. One is that knowledge of the effects of water near its critical point on elementary reactions is incomplete and still evolving. SCF solvent effects such as clustering, hydrogen bonding, or cage effects have been implicated in previous studies ${ }^{1,4,22,26}$ of reactions in an SCF near its critical temperature. Moreover, there are uncertainties in the kinetics and mechanism we used for methane oxidation in $\mathrm{SCW}$. Some of these uncertainties arise from neglecting fluid-phase nonidealities when determining the kinetics of the reverse reactions. The inability to calculate fugacity coefficients for radicals in SCW prevented us from accounting for this effect. A degree of uncertainty also exists in the detailed kinetics models for the gas-phase partial oxidation of methane and the role of homogeneous and heterogeneous reactions. ${ }^{46}$ One recent model,${ }^{47}$ which required "enhancement factors" of up to $10^{6}$ for some steps

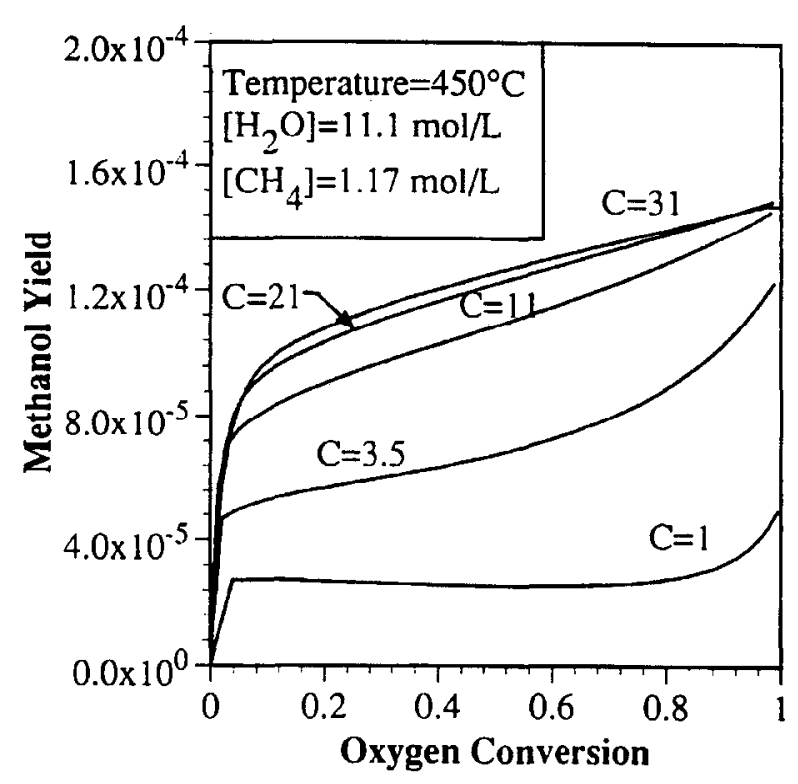

Figure 3. Effect of oxygen conversion and $\left[\mathrm{CH}_{4}\right]_{0} /\left[\mathrm{O}_{2}\right]_{0}$ ratio (denoted as $\mathrm{C}$ ) on methanol yield at $450^{\circ} \mathrm{C}$

to obtain quantitative agreement with experiments, offers an extreme example. Finally, the model that we used excluded reactions that may be important under our conditions. For example, the model excludes reactions that lead to $\mathrm{C}_{2}$ products. These steps were unimportant under Webley and Tester's experimental conditions, but they could contribute under the present conditions, which use lower temperatures and oxygen as the limiting reactant.

The discussion above leads us to conclude that quantitative a priori prediction of methane oxidation rates and methanol selectivities near the critical temperature cannot be expected from current detailed kinetics models. This realization motivated our use of the Webley and Tester model. ${ }^{21}$ We made no attempt to improve the mechanism or the rate constant estimates. Again, we emphasize that our primary motivation for performing this modeling study was to take advantage of an existing complementary method for exploring the feasibility of converting methane to methanol in SCW. Therefore, we next used the elementary reaction model to accomplish our primary goal for this portion of the work.

Figures 3-6 show the effects of the extent of reaction (as measured by the oxygen conversion), temperature, and the initial methane to oxygen molar ratio on the calculated methanol yield and selectivity. Figures 3 and 4 show the influence of these parameters on the methanol yield for cases where the temperature is held constant at $450{ }^{\circ} \mathrm{C}$ and where the methane to oxygen molar ratio is held constant at 16 . In all cases, the methanol yields are very low $(<0.2 \%)$. The predicted yield increases with increasing methane to oxygen molar ratios (denoted as $\mathrm{C}$ in the figures), with increasing oxygen conversion, and with increasing temperature. Figures 5 and 6 display the ef- 


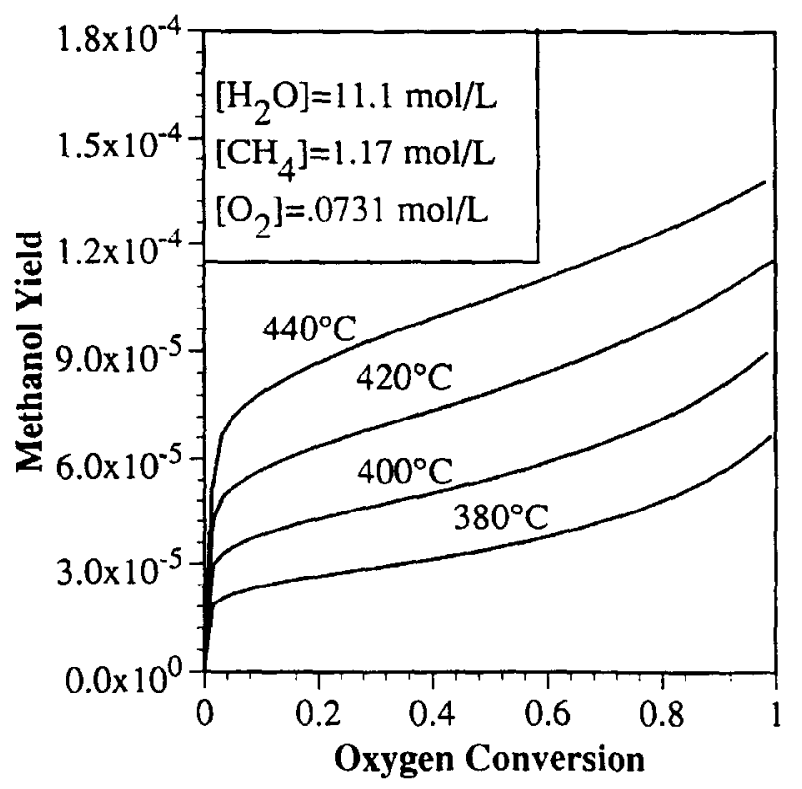

Figure 4. Effect of oxygen conversion and temperature on methanol yield at $\left[\mathrm{CH}_{4}\right]_{0} /\left[\mathrm{O}_{2}\right]_{0}=16$.

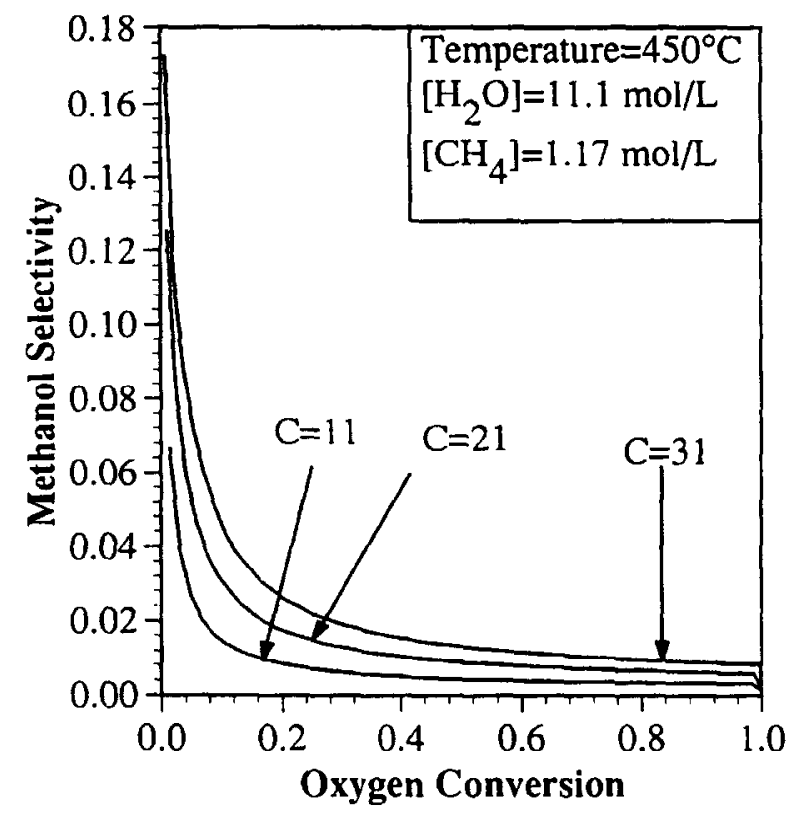

Figure 5. Effect of oxygen conversion and $\left[\mathrm{CH}_{4}\right]_{0} /\left[\mathrm{O}_{2}\right]_{0}$ ratio (denoted as $\mathrm{C}$ ) on methanol selectivity at $450^{\circ} \mathrm{C}$

fects of these same parameters on the methanol selectivity. Here, we see that for a fixed oxygen conversion the selectivity increases with temperature and with the methane to oxygen ratio. The highest selectivities appear at low oxygen conversions.

Some of the trends discussed above for the present mechanistic model for methane oxidation in SCW were also evident in recent models $\mathrm{s}^{47,48}$ of methane oxidation in the gas phase at pressures around $50 \mathrm{~atm}$. For example, Danen et al. ${ }^{48}$ reported that the methanol selectivity increased with temperature, but decreased with conversion.

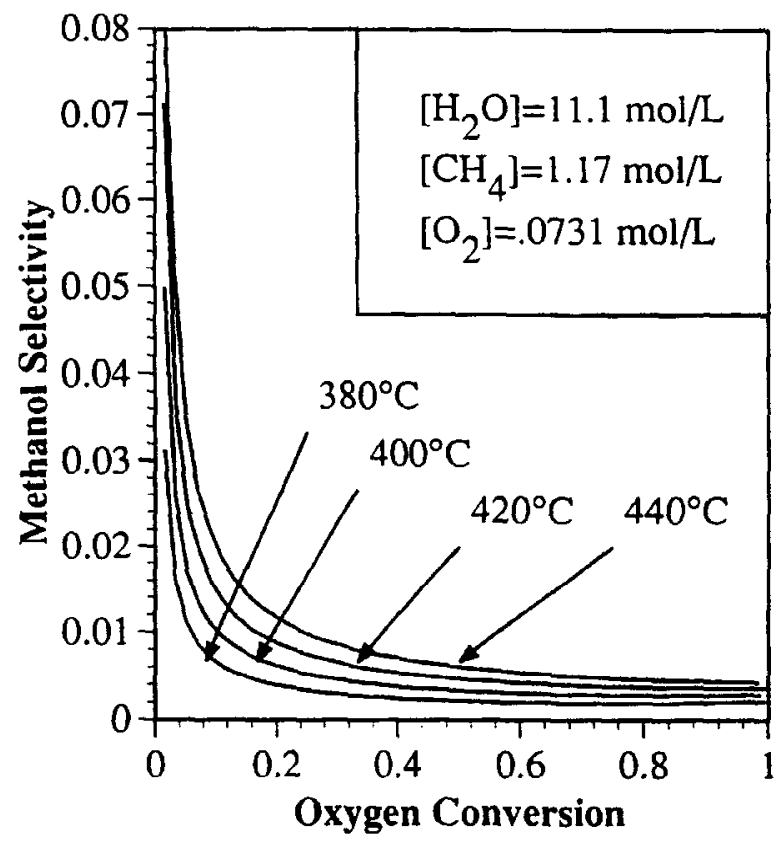

Figure 6. Effect of oxygen conversion and temperature on methanol selectivity at $\left[\mathrm{CH}_{4}\right]_{0} /\left[\mathrm{O}_{2}\right]_{0}=16$.

Chun and Anthony ${ }^{47}$ reported that the methanol selectivity increased with the initial methane to oxygen molar ratio. Both of these models predicted higher methanol selectivities and much higher yields than did the present model for oxidation in SCW.

\section{CONCLUSIONS}

1. Methane can be converted to methanol by partial oxidation in supercritical water. The high methanol selectivitics obscrved expcrimentally compare favorably with the best results from gas-phase methane oxidation. Unlike the gas-phase oxidation, however, these high selectivities for oxidation in SCW were obtained only at very low methane conversions of less than $0.1 \%$. Higher methane conversions resulted in higher methanol yields, but at the expense of diminished selectivity. The highest methanol yield was $0.7 \%$. These yields may be too low to make the partial oxidation of methane in SCW a commercially viable technology.

2. Partial oxidation reactions in glass-lined reactors gave higher conversions and lower selectivities to methanol than did reactions under otherwise identical conditions in stainless-steel reactors. Under one set of conditions where the methanol yield was very low in stainlesssteel reactors, conducting the reaction in a glass-lined reactor increased the yield by nearly an order of magnitude. Under a different set of conditions, however, where the highest yields were obtained in the stainless-steel reactors, switching to a glass-lined reactor had no apparent effect on the yield.

3. In addition to methanol, trace amounts of other oxygenated hydrocarbons formed during the partial oxida- 
tion of methane in SCW. These trace products have been tentatively identified as acetaldehyde, ethanol, acetic acid, and formic acid.

4. A detailed chemical kinetics model for methane oxidation in SCW predicted that methanol yields would be low $(\approx 0.01 \%)$ within the parameter space studied. The yield was predicted to increase with temperature, oxygen conversion, and the initial methane to oxygen molar ratio. The methanol selectivity was highest at low oxygen conversions, and the selectivity increased with temperature and the initial methane-to-oxygen molar ratio.

\section{ACKNOWLEDGMENTS}

Leonard Buccellato and Scott Schneider helped to develop the experimental procedures. Eric Brock assisted with the modeling work. We acknowledge helpful discussions with Professor John Barker about mechanistic modeling, and we thank Professor Jeff Tester for providing thermodynamics and kinetics data for the elementary reactions. This research was supported in part by the Office of the Vice-President for Research at the University of Michigan and by an REU Supplement to grant CTS9015738 from the National Science Foundation.

\section{REFERENCES}

(1) Wu, B. C.; Klein, M. T.; Sandler, S. I. Ind. Eng. Chem. Res. 1991, 30, 822 .

(2) Hrnjez, B. J.; Mehta, A. J.; Fox, M. A.; Johnston, K. P. J. Am. Chem. Soc. 1989, 111, 2662.

(3) Johnston, K. P.; Haynes, C. AlChE J. 1987, 33, 2017.

(4) Peck, D. G.; Mehta, A. J.; Johnston, K. P. J. Phys. Chem. 1989, 93, 4297.

(5) Aida, T.; Squires, T. G. In Supercritical Fluids: Chemical and Engineering Principles and Applications; Squires, T. G.; Paulaitis, M. E., Eds. ACS Symposium Series 329; American Chemical Society: Washington, DC, 1987.

(6) Antal, M. J.; Brittain, A.; DeAlmeida, C.; Ramayya, S.; Roy, J. C. In Supercritical Fluids: Chemical and Engineering Principles and Applications; Squires, T. G.; Paulaitis, M. E., Eds. ACS Symposium Series 329; American Chemical Society: Washington, DC, 1987.

(7) Xu, X.; DeAlmeida, C. P.; Antal, M. J. Ind. Eng. Chem. Res. 1991, 30, 1478.

(8) Narayan, R.; Antal, M. J. In Supercritical Fluid Science and Technology; Johnston, K. P.; Penninger, J. M. L., Eds.; ACS Symposium Series 406; American Chemical Society: Washington, DC, 1989.

(9) Houser, T. J.; Tiffany, D. M.; Li, Z.; McCarville, M. E.; Houghton, M. E. Fuel 1986, 65, 827.

(10) Houser, T. J.; Tsao, C.; Dyla, J. E.; VanAtten, M. K.; McCarville, M. E. Fuel 1989, 68, 323.

(11) Townsend, S. H.; Abraham, M. A.; Huppert, G. L.; Klein, M. T.; Paspek, S. C. Ind. Eng. Chem. Res. $1988,27,143$.

(12) Huppert, G. L.; Wu, B. C.; Townsend, S. H.; Klein, M. T,; Paspek, S. C. Ind. Eng. Chem. Res. 1989, 28, 161.
(13) Penninger, J. M. L.; Kolmschate, J. M. M. In Supercritical Fluid Science and Technology; Johnston, K. P.; Penninger, J. M. L., Eds.; ACS Symposium Series 406; American Chemical Society: Washington, DC, 1989.

(14) Lawson, J. R.; Klein, M. T. Ind. Eng. Chem. Fundam. 1985, 24, 203.

(15) Abraham, M. A.; Klein, M. T. In Supercritical Fluids: Chemical and Engineering Principles and Applications; Squires, T. G.; Paulaitis, M. E., Eds.; ACS Symposium Series 329; American Chemical Society: Washington, DC, 1987.

(16) West, M. B.; Gray, M. R. Can. J. Chem. Eng. 1987, 65,645 .

(17) Siskin, M.; Katritzky, A. R. Science 1991, 254, 231.

(18) Thornton, T. D.; Savage, P. E. AlChE J. 1992, 38, 321.

(19) Li, R.; Szmukler, D.; Savage, P. E. AIChE J. 1993, $39,178$.

(20) Thornton, T. D.; Savage, P. E. Ind. Eng. Chem. Res. 1992, 31, 2451.

(21) Webley, P. A.; Tester, J. W. Energy \& Fuels 1991, 5, 411.

(22) Yang, H. H.; Eckert, C. A. Ind. Eng. Chem. Res. 1988, 27, 2009.

(23) Jin, L.; Ding, Z.; Abraham, M. A. Chem. Eng. Sci. $1992,47,2659$.

(24) Lee, D. S.; Gloyna, E. F. Env. Sci. Technol. 1992, $26,1587$.

(25) Flarsheim, W. M.; Tsou, Y.; Trachtenberg, 1.; Johnston, K. P.; Bard, A. J. J. Phys. Chem. 1986, 90, 3857.

(26) Flarsheim, W. M.; Bard, A. J.; Johnston, K. P. $J$. Phys. Chem. 1989, 93, 4234.

(27) Franck, E. U. Proc. of 2nd Intl. Symp. on Supercrit. Fluids 1991, p 91.

(28) Dixon, C. N.; Abraham, M. A. J. Supercrit. Fluids $1992,5,269$.

(29) Labinger, J. A. ACS Div. Pet. Chem. Prepr. 1992, 289.

(30) Periana, R. A.; Taube, D. J.; Evitt, E. R.; Löffler, D. G.; Wentrcek, P. R.; Voss, G.; Masuda, T. Science 1993, 259, 340.

(31) Steeper, R. R.; Rice, S. F.; Brown, M. S.; Johnston, S. C. J. Supercrit. Fluids 1992, 5, 262.

(32) Rofer, C. K.; Streit, G. E. LA-11439-MS, DOE/HWP. 641988.

(33) Rofer, C. K.; Streit, G. E. LA-11700-MS, DOE/HWP901989.

(34) Diamond, W. J. Practical Experiment Designs for Engineers and Scientists; Lifetime Learning Publications: Belmont, CA, 1981.

(35) Box, G. E. P.; Hunter, W. G.; Hunter, J. S. Statistics for Experimenters; John Wiley \& Sons: New York, 1978.

(36) Reid, R. C.; Prausnitz, J. M.; Sherwood, T. K. The Properties of Gases and Liquids, 3rd edition, McGraw Hill: New York, 1977, p. 140.

(37) Methane Conversion by Oxidative Processes; Wolf, E. E., Ed.; Van Nostrand Reinhold: New York, 1992.

(38) Gesser, H. D.; Hunter, N. R.; Prakash, C. B. Chem. Rev. 1985, 85, 235.

(39) Rytz, D. W.; Baiker, A. Ind. Eng. Chem. Res. 1991, $30,2287$.

(40) Thomas, D. J.; Willi, R.; Baiker, A. Ind. Eng. Chem. Res. 1992, 31, 2272. 
144 Savage et al.

(41) Yarlagadda, P. S.; Morton, L. A.; Hunter, N. R.; Gesser, H. D. Ind. Eng. Chem. Res. 1988, 27, 252.

(42) Burch, R.; Squire, G. D.; Tsang, S. C. J. Chem. Soc. Faraday Trans. I 1989, 85, 3561.

(43) Chun, J.; Anthony, R. G. Ind. Eng. Chem. Res. 1993, $32,259$.

(44) Tester, J. W., personal communication, 1993.
(45) Braun, W.; Herron, J. T.; Kahaner, D. K. Int. J. Chem. Kinet. 1988, 20, 51.

(46) Mackie, J. C. Catal. Rev. - Sci. Eng. 1991, 33, 169.

(47) Chun, J.; Anthony, R. G. Ind. Eng. Chem. Res. 1993, $32,796$.

(48) Danen, W. C.; Ferris, M. J.; Lyman, J. L.; Oldenborg, R. C.; Rofer, C. K.; Streit, G. E. ACS Div. Pet. Chem. Prepr. 1991, 36, 166. 